\title{
SHEAR DAMAGE MODELLING OF RC BEAMS USING SIMPLIFIED APPROACH TO MODEL STEEL-CONCRETE INTERFACE
}

\author{
SHOAIB AHMAD GORAYA ${ }^{*}$, KH RAHAT USMAN ${ }^{\dagger}$ AND RASHID HAMEED ${ }^{\dagger \dagger}$ \\ *University of Engineering \& Technology (UET), Lahore \\ Lahore, Pakistan \\ e-mail: shoaibgoraya28@gmail.com \\ ${ }^{\dagger}$ University of Engineering \& Technology (UET), Lahore \\ Lahore, Pakistan \\ e-mail: rahat_libra09@hotmail.com \\ ${ }^{\dagger \dagger}$ University of Engineering \& Technology (UET), Lahore \\ Lahore, Pakistan \\ e-mail: rashidmughal@uet.edu.pk
}

Key words: RC beam; shear failure; damage modelling; steel-concrete interface; FE code CASTEM

\begin{abstract}
To avoid expensive and time consuming experimentation to study the behavior of structural elements subjected to different mode of loadings, numerical simulation techniques are of great importance. In the research study presented in this contribution, damage modelling of RC beam failing in shear was carried out. Mazars damage model for plain concrete and elastic perfectly plastic behavior law for steel bars were adopted for finite element modelling in finite element (FE) code CASTEM. Since the correct description of cracking process in RC structural element mainly depends upon the behavior of steel rebar-concrete interface, a simplified approach which considers the introduction of massive elasto-plastic isotropic bond element as steel rebar-concrete interface is considered in this study. In order to validate the numerical simulation results, a comprehensive experimental program was designed and carried out. Under this program, third point bending test on $\mathrm{RC}$ beams weak in shear were performed along with some classical tests on concrete specimens to get the values of some model parameters. Comparison of modelling and experimental results was carried out in terms of load-deflection response. The results of numerical simulation showed close agreement with the experimental observations. The ability of the finite element modelling technique adopted in this study to predict damage and cracking pattern in shear is also highlighted in this paper.
\end{abstract}

\section{INTRODUCTION}

After earthquake of 2005 in Pakistan, it has been observed that many existing $\mathrm{RC}$ structures require strengthening and retrofitting. Mechanical properties of concrete used in existing structural elements may be determined through Non Destructive Testing (NDT) and the same may be used to predict 
their response when subjected to different mode of loadings by employing various available analytical procedures. However, in order to predict damage and cracking response with respect to serviceability limit state requirements of many codes, numerical simulation by using any of the fracture mechanics based behavior laws is essential. In this regard, behavior laws which require values of the model parameter which can be determined through performing classical tests on concrete in laboratories are always of great interest.

Keeping in mind the importance of numerical modelling of RC structures, this study has been carried out to understand the shear damage modelling of RC concrete beam using finite element method. Mazar damage model [1] for plain concrete and elastic perfectly plastic behavior law for steel bars were adopted for finite element modelling in finite element (FE) code CASTEM [2]. Since the correct description of cracking process in $\mathrm{RC}$ structural element mainly depends upon the behavior of steel rebar-concrete interface [3], a simplified approach which considers the introduction of massive elasto-plastic isotropic bond element as steel rebar-concrete interface [4] is considered in this study. In order to validate the numerical simulation results, a comprehensive experimental program was designed and carried out to get experimental results.

\section{MODEL PRESENTATION}

Reinforced concrete (RC) is modelled as an equivalent three phase material (figure 1). It consists of;

1. Massive concrete with damage model

2. Steel-concrete interface with cubic element
3. Uniaxial bar element with cross sectional area and material properties same as that of steel bar.

\subsection{Plain Concrete Model}

The plain concrete has been modeled using classical Mazars model [1]. This model is based on the damage continuum mechanics. It is an isotropic damage model, which considers the dissymmetry between tension and compression responses. It is considered as a reference model in the concrete modelling by reason of its simplicity and robustness, and it allows simulation of complete large structures without convergence problems [5].

\subsection{Behavior Law of Steel Reinforcing Bars}

An elastic perfectly plastic behavior law is used to model the steel reinforcing bars in this study. In most of the commercially available finite element codes, this type of behavior law for steel reinforcing bars is generally available.

\subsection{Steel-Concrete Interface}

The method adopted to model the interface between steel and concrete is shown schematically in figure 1 [4]. In this method, area of steel bar is replaced by the equivalent system of interface bond element and steel which is square in shape to simplify its integration in finite element mesh based on cubic elements. The dimensions of square interface bond element are deduced from the diameter of the steel bar to conserve the global stiffness of the reinforced concrete element. In order to keep the global stiffness of the composite same in the elastic range for the two cases shown in figure $2, \alpha$ is defined as the ratio between elastic modulus of the interface bond element $E_{i}$ and elastic modulus of massive concrete $E_{c}$. The steel bar is modeled 
as uniaxial element located at the centre of square interface element whereas the behavior of interface bond element is assumed to be elastic-plastic isotropic governed by a multinonlinear yielding curve deduced from a pullout test (figure 3 ).

Let the global stiffness of the two equivalent systems shown in figure 2 is $K_{o}$, combined stiffness of the two phase system shown in figure 2 (on left) and three phase system in figure 2 (on right) is given in equations 1 and 2, respectively.

$$
\begin{gathered}
E_{c}\left(A_{c}-A_{s}\right)+E_{s} A_{s}=K_{o} \\
E_{c}\left(A_{c}-A_{i}\right)+E_{i} A_{i}+E_{s} A_{s}=K_{o}
\end{gathered}
$$

By equating equations 1 and 2, we obtain;

$$
E_{c}\left(A_{c}-A_{s}\right)+E_{s} A_{s}=E_{c}\left(A_{c}-A_{i}\right)+E_{i} A_{i}+E_{s} A_{s}
$$

From the equation 3, expression for the ratio of elastic modulus of interface bond element and massive concrete is obtained as;

$$
\frac{E_{i}}{E_{c}}=1-\frac{A_{s}}{A_{i}} \quad \Leftrightarrow \alpha=1-\frac{A_{s}}{A_{i}}
$$

Consequently the section of the interface element has to be chosen as a function of alpha.

$$
A_{i}=\frac{A_{s}}{1-\alpha}
$$

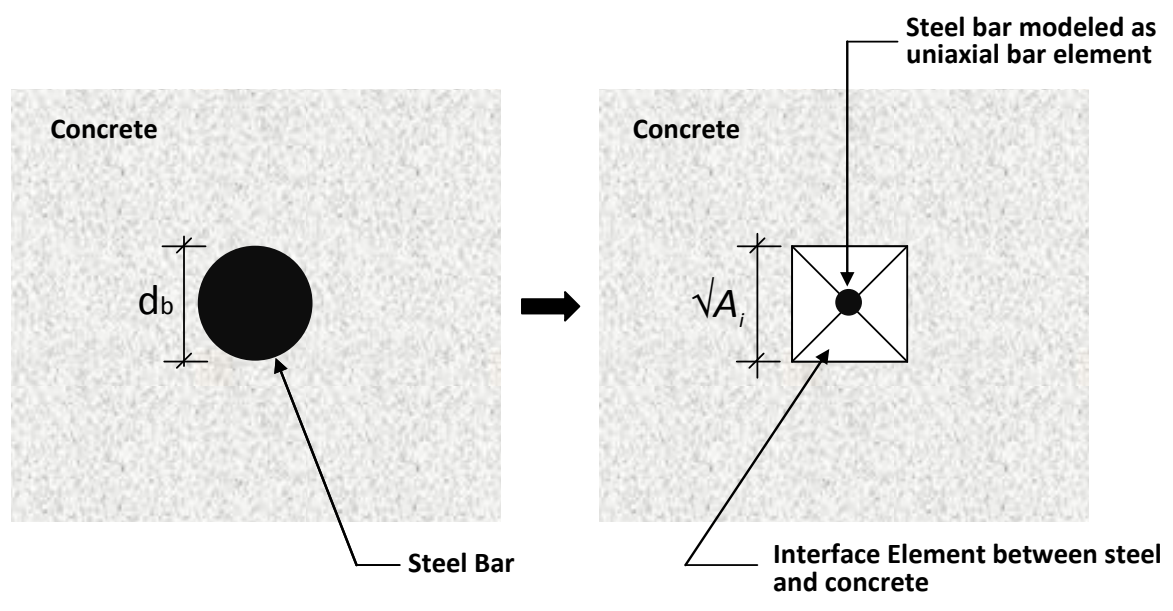

Figure 1: Method to model interface between steel rebar and concrete

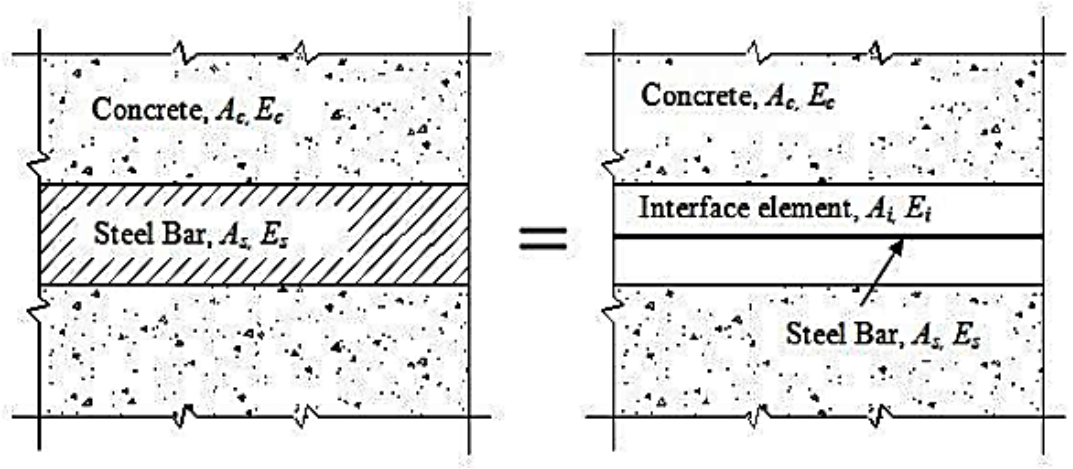

Figure 2: Global stiffness of two equivalent systems 


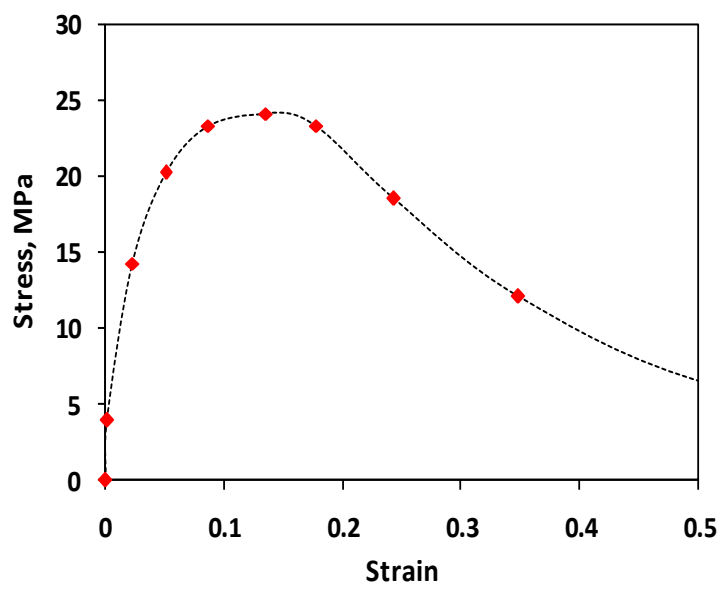

Figure 3: Uniaxial multi-linear hardening curve used to model interface bond element [4]

It is important to mention here that shear modulus is also a fitting parameter needed to control initial shear stiffness of the interface independently of the axial modulus computed as explained in equations 1 to 5 . The plastic criterion used in the interface is based on von Mises one, without dilatancy, but with the non-linear hardening curve as shown in figure 3. In the interface zone, the constitutive behavior law is $\sigma=S\left(\varepsilon-\varepsilon^{p l}\right)$ and $\varepsilon^{p l}$ is the interface plastic strain derived from the standard plasticity theory based on von Mises criterion with the non-linear hardening, which is a very robust plastic law. The plastic dissipation during sliding takes place in a controlled volume depending on the reinforcement diameter. The correct dissipation is obtained by a direct fitting of the plastic hardening law on a pull out test (inverse analysis).

\section{EXPERIMENTAL PROGRAM}

In this research study, an experimental program is designed in addition to numerical simulation to validate the model results. To study the shear damage behavior of RC beams, an RC beam without shear reinforcement is casted. The beam is tested under three point loading to get experimental crack pattern of
RC beam. Details of test specimen, materials and testing setup are given below:

\subsection{Test Specimen}

The test beam was of cross section 3" $\mathrm{x} 6$ " (75 x $150 \mathrm{~mm})$ and length 54" (1350 mm). Beam was designed to fail in shear and not in flexure so no transverse reinforcement was provided and sufficient flexural reinforcement was provided to achieve shear failure. Flexural reinforcement consisted of $2 \# 13$ (US Customary) bars, while 2\#10 bars were provided as hanger bars at the top. The cross section and the longitudinal profile of beam are presented below (figure 4).

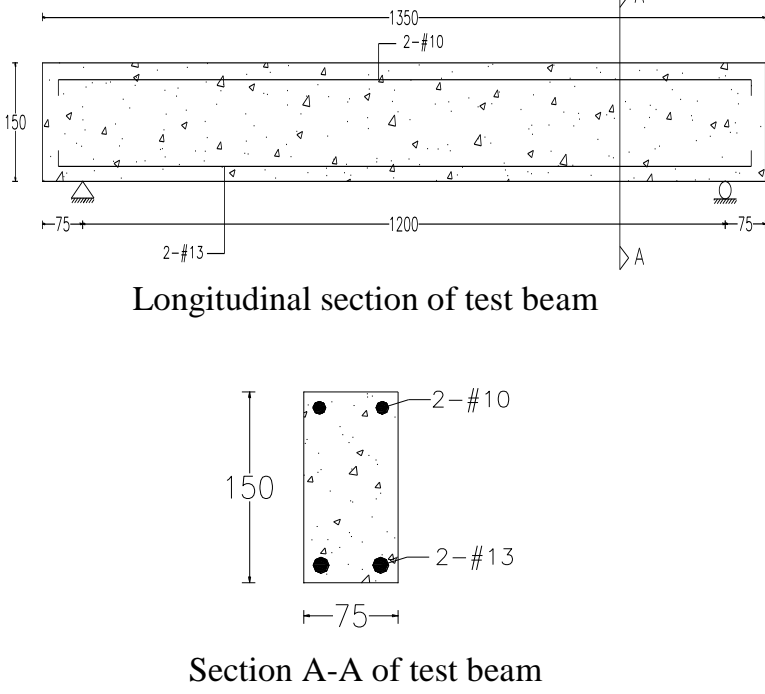

Figure 4: Reinforcement detail of test specimen (RC beam)

\subsection{Experimental Setup}

Third point bending test was performed on the beam using Universal Testing Machine having maximum loading capacity of $1000 \mathrm{kN}$ in flexure. The machine was connected to data acquisition system. The test was displacement controlled and was performed at an imposed displacement rate of $2 \mathrm{~mm}$ per minute. The testing setup is shown in figure 5 . 


\subsection{Experimental Observations}

During testing, corresponding to each imposed displacement level, force and mid span deflection of the beam were measured using digital load cell and LVDT, respectively and the data were automatically recorded using data acquisition system. The experimental cracking pattern of test specimen was also observed and is shown in figure 6 , where it can be noticed that beam failed in shear clearly developing diagonal cracks.

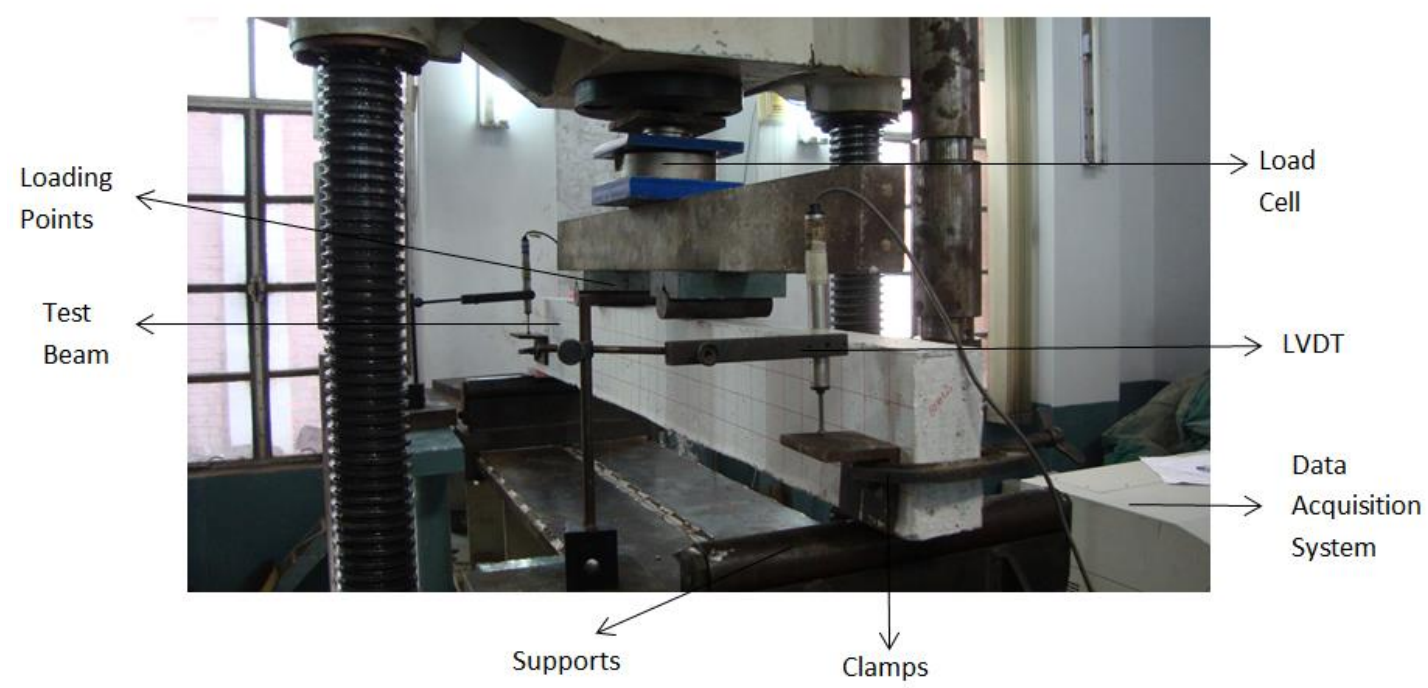

Figure 5: Experimental Setup

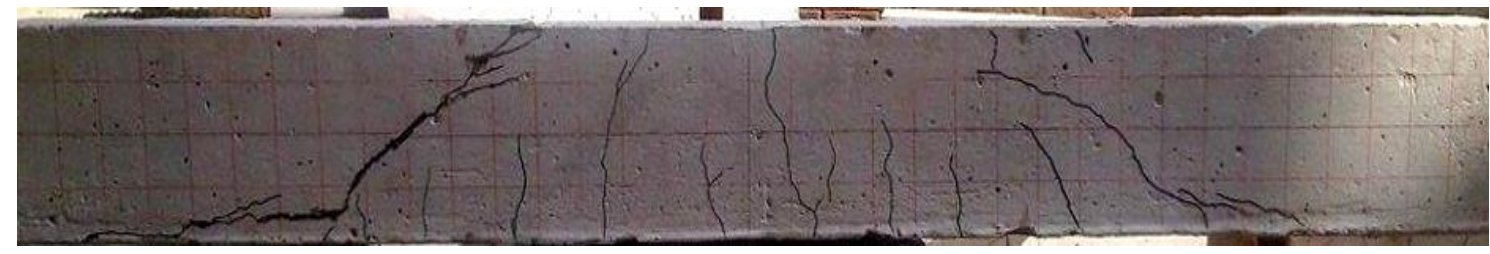

Figure 6: Experimental Crack Pattern

\section{MODEL FITTING \& VALIDATION}

In this part of the paper, fitting and validation of the method employed to model the interface between steel reinforcing bars and concrete matrix for reinforced concrete element is carried out. For this purpose, two different types of tests are simulated: pull-out test on cubic specimen for model fitting and third point bending tests on $\mathrm{RC}$ beam for the validation of modelling approach. As mentioned earlier, for numerical simulation, finite element code CASTEM was employed.

\subsection{Fitting of Model Parameters}

Fitting of different model parameters was performed through simulating the pull-out test. Three dimensional finite element mesh of the pull-out test specimen made in CASTEM is shown figure 7 which provides all necessary information about the boundary conditions and symmetrical surfaces. In the simulation of pull-out test, considering the double symmetry of the problem one fourth of the specimen is modelled to reduce computation time. The 
values of different model parameters given in

table 1-3 were obtained through experiments.

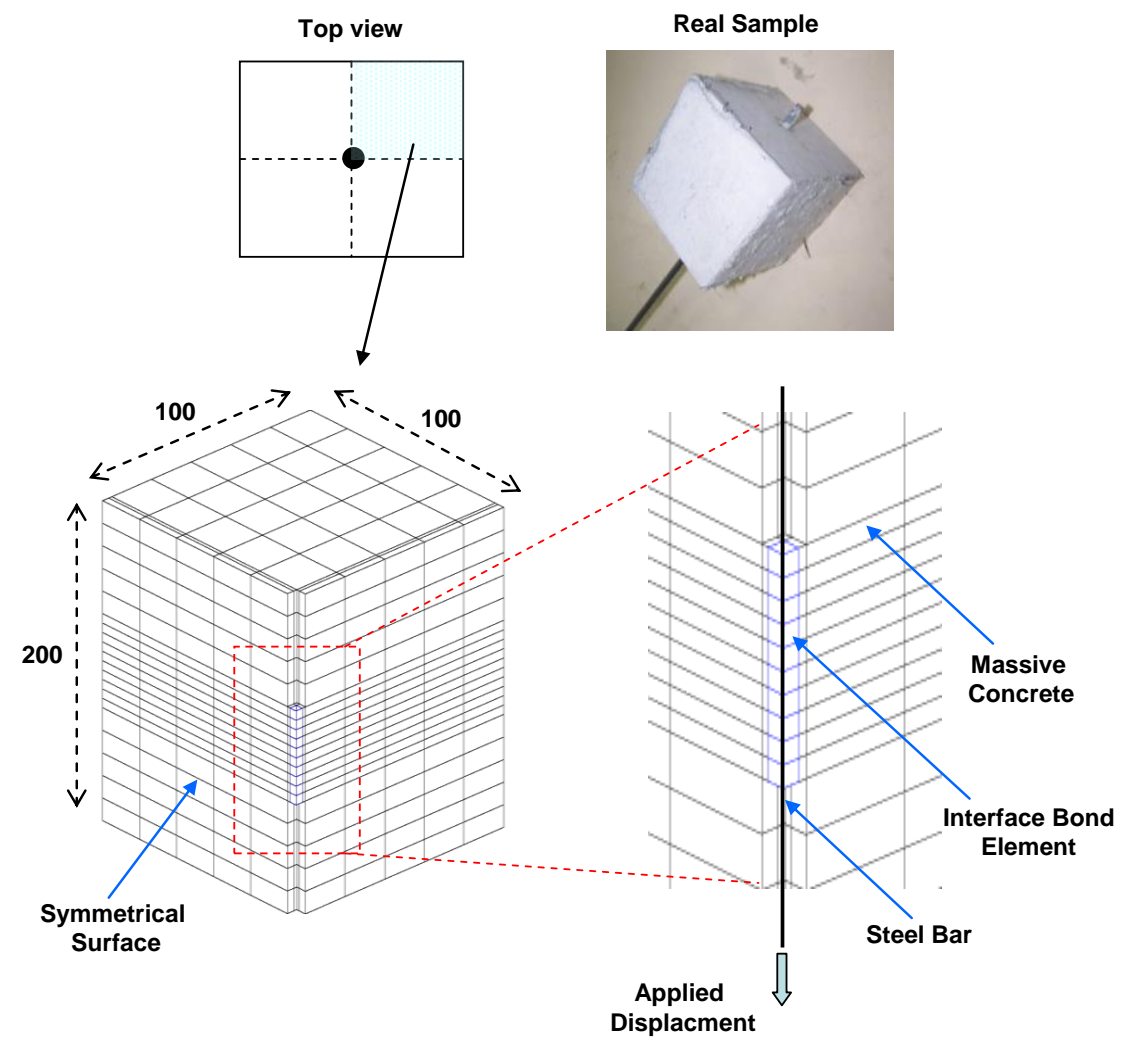

Figure 7: 3D finite element mesh of one fourth of pull-out test specimen

Table 1: Parameters for damage model of massive concrete

\begin{tabular}{llll}
\hline Parameter & Notation & Value & Unit \\
\hline Young Modulus & $\mathrm{E}$ & 24870 & $\mathrm{MPa}$ \\
\hline Poisson Ratio & $\mathrm{Y}$ & 0.2 & - \\
\hline Density of Concrete & $\mathrm{P}$ & 2400 & $\mathrm{~kg} / \mathrm{m}^{3}$ \\
\hline Compressive Strength & $\mathrm{f}_{\mathrm{c}}$ & 28 & $\mathrm{MPa}$ \\
\hline Model Parameter, $\mathrm{B}_{\mathrm{t}}$ & $\mathrm{B}_{\mathrm{t}}$ & 1700 & - \\
\hline Model Parameter, $\mathrm{B}_{\mathrm{c}}$ & $\mathrm{B}_{\mathrm{c}}$ & 1900 & - \\
\hline Model Parameter, $\mathrm{A}_{\mathrm{t}}$ & $\mathrm{A}_{\mathrm{t}}$ & 0.8 & - \\
\hline Model Parameter, $\mathrm{A}_{\mathrm{c}}$ & $\mathrm{A}_{\mathrm{c}}$ & 1.4 & - \\
\hline $\begin{array}{l}\text { Parameter Selected } \\
\text { for Shear Behavior }\end{array}$ & $\mathrm{B}$ & 1.06 & - \\
\hline
\end{tabular}

Table 2: Model parameters for interface bond element behaviour law as elasto-plastic

\begin{tabular}{llll}
\hline Parameter & Notation & Value & Unit \\
\hline Young's Modulus & $\mathrm{E}$ & 8334.71 & $\mathrm{MPa}$ \\
\hline Poisson coefficient & $\mathrm{Y}$ & 0.2 & - \\
\hline Stress-Strain Curve & \multicolumn{4}{l}{ Obtained from pull-out test } \\
\hline
\end{tabular}

Table 3: Parameters for the model of steel bars behaviour law as elastic-plastic perfect

\begin{tabular}{llll}
\hline Parameter & Notation & Value & Unit \\
\hline Young modulus & $\mathrm{E}$ & 200 & $\mathrm{GPa}$ \\
\hline Poisson's ratio & $v$ & 0.2 & - \\
\hline Cross sectional area & $A_{s}$ & 129 & $\mathrm{~mm}^{2}$ \\
\hline Yielding strength & $f_{y}$ & 420 & $\mathrm{MPa}$ \\
\hline
\end{tabular}

Fitted load versus slip response from the numerical modelling was compared with experimental data and is presented in figure.8. This figure shows the ability of the approach adopted to model the interface between steel reinforcement and concrete matrix as the model predict quite well the load-slip response in the pull-out test simulation. 


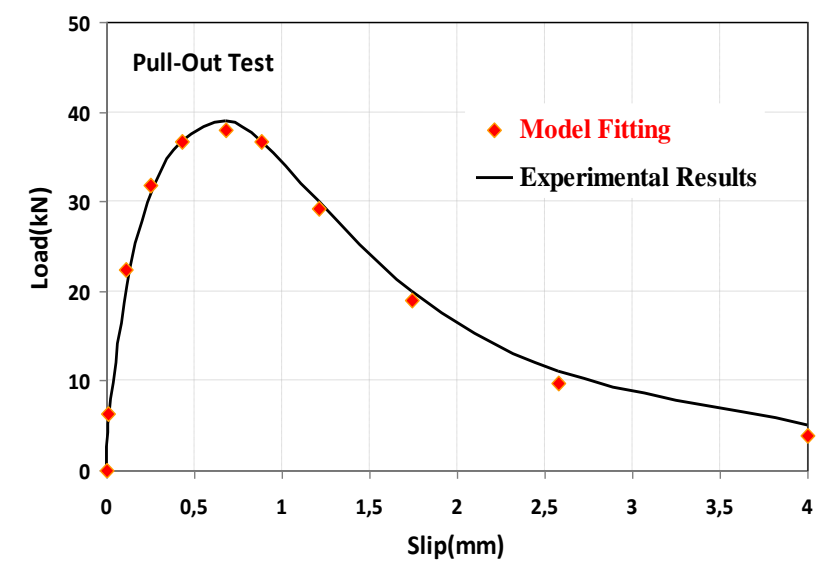

Figure 8: Pull-out test simulation result (model fitting)

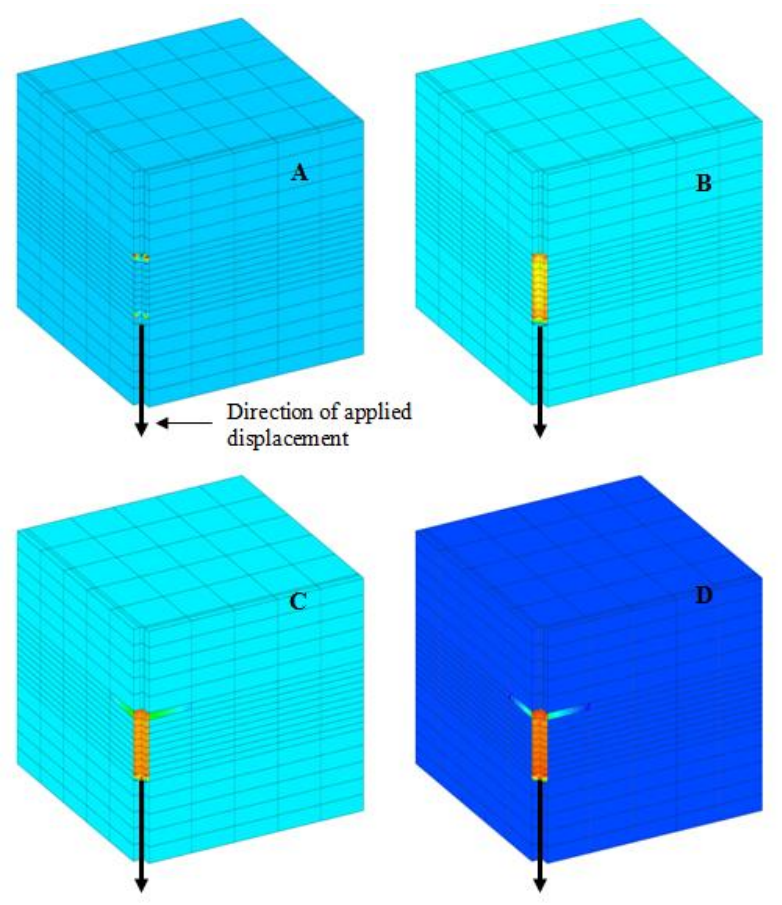

Figure 9: Damage evolution in concrete in pull-out test

Damage evolution in the finite element mesh of massive concrete at the contact surface with the steel bar is shown in figure 9, where progressive damage with the increase of steel bar slip can be observed.

\subsection{Model Validation: Reinforced Concrete Beam}

In this section, the adopted method to model the interface between steel bar and concrete is used to simulate the behaviour of reinforced concrete beam. Finite element meshing of RC beam in CASTEM is shown in figure 10. Span length and cross-sectional dimension of test specimen (beam) are also given in the same figure along with geometrical details of interface element. In the model, the loading was applied through an imposed vertical displacement in the mid span.

The boundary conditions are shown in figure 11. Only a quarter of the beam (figure 12) was analyzed thanks to the double symmetry of the problem. Comparison of modelling and experimental results in terms of load-deflection curves is shown in figure 13, where it is observed that model predictions are in good agreement with the experimental observations. The computed damage pattern is presented in figure 14 . The capability of modelling techniques adopted in this study to compute damage is quite evident in these figures. Simulation results in terms of shear damage pattern and cracking pattern were also found in close agreement with the experimental observations.

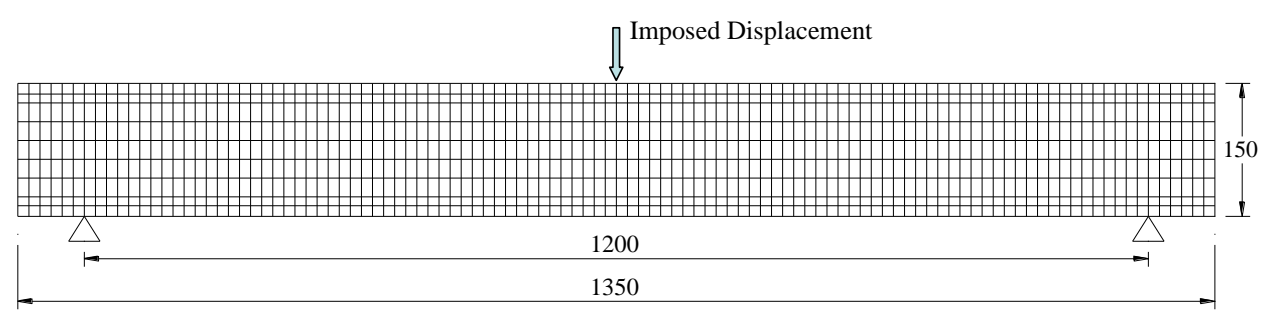




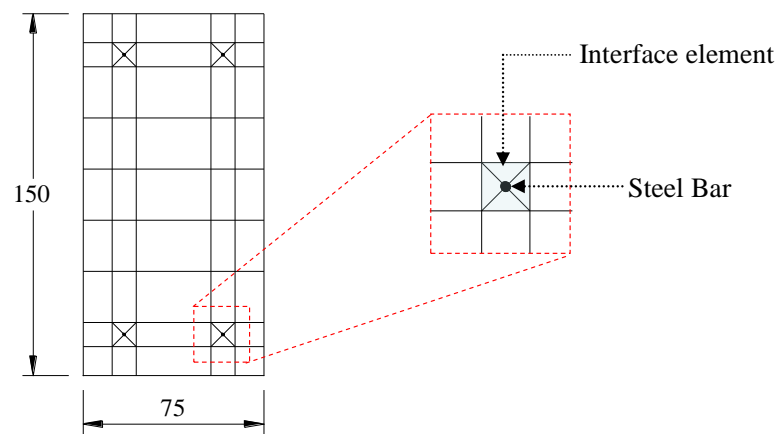

Beam Cross Section

Figure 10: Finite element mesh of reinforced concrete beam

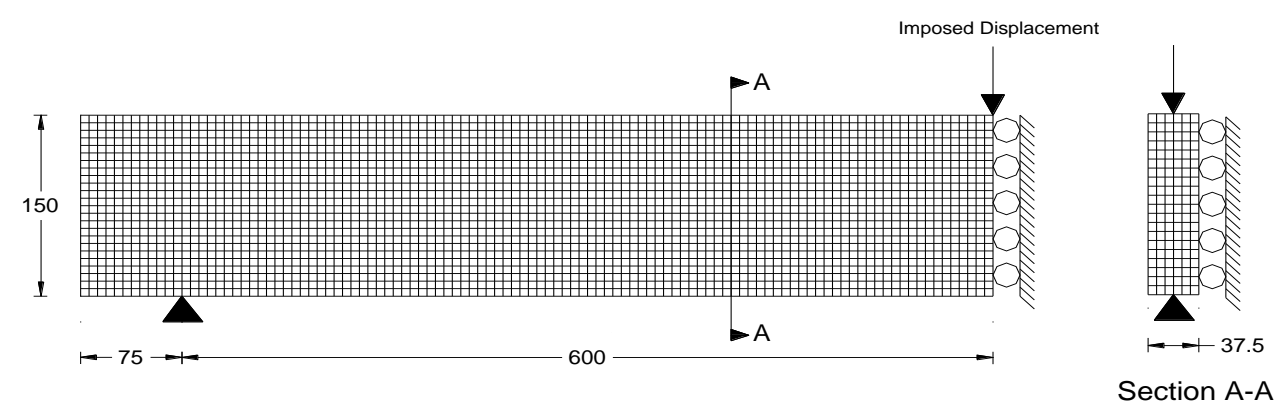

Figure 11: Finite element mesh of reinforced concrete beam
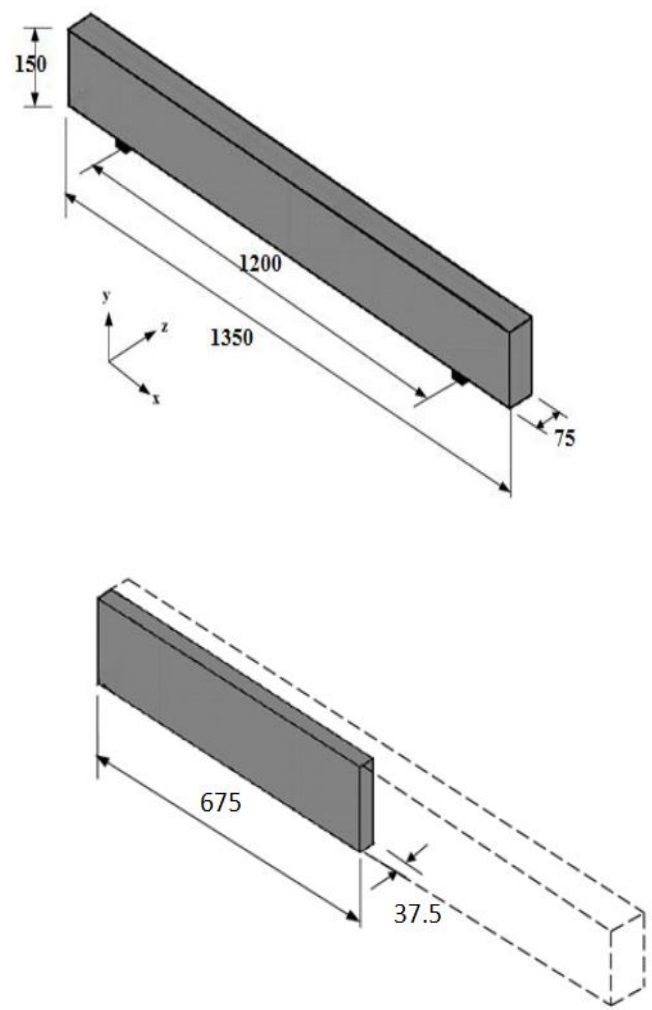

Figure 12: One fourth of RC beam to be modelled

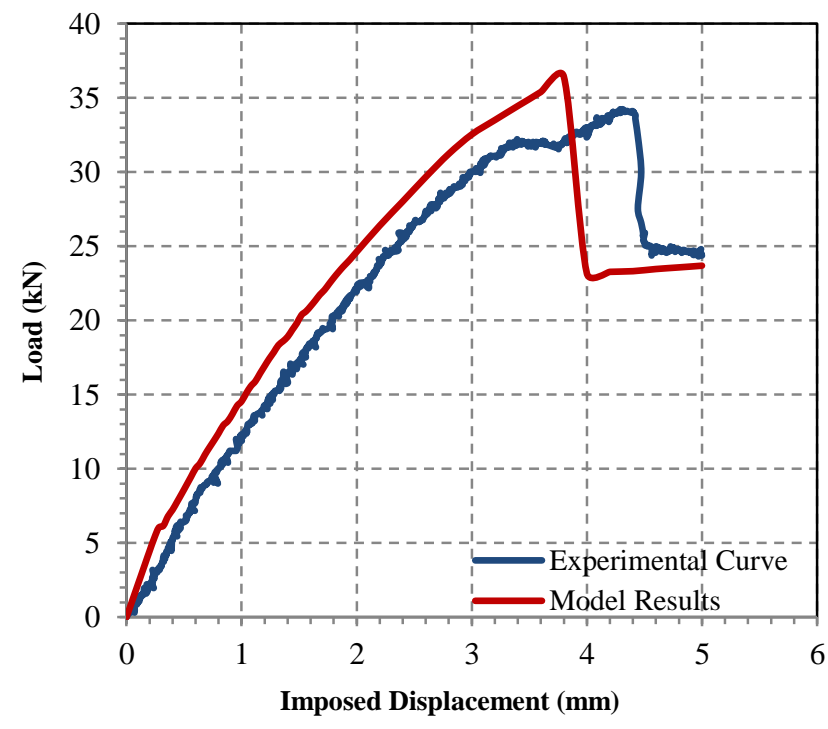

Figure 13: Comparison of experimental and computed load-deflection curves 
Deflected shape of RC beam in CASTEM

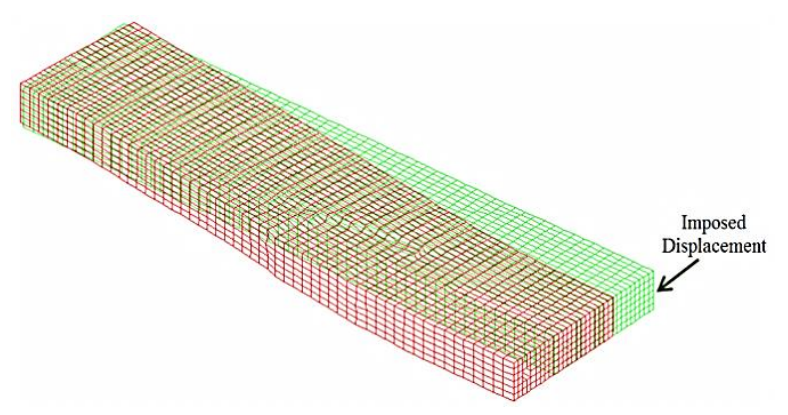

Deflection $=0.8 \mathrm{~mm}$, Load $=10.0 \mathrm{kN}$

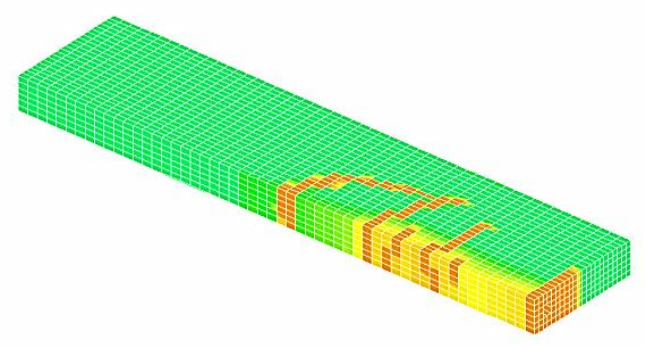
Deflection $=1.6 \mathrm{~mm}$, Load $=18.3 \mathrm{kN}$

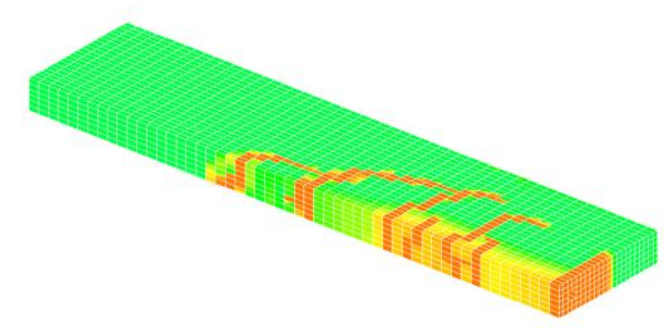

Deflection $=3.0 \mathrm{~mm}$, Load $=30.0 \mathrm{kN}$

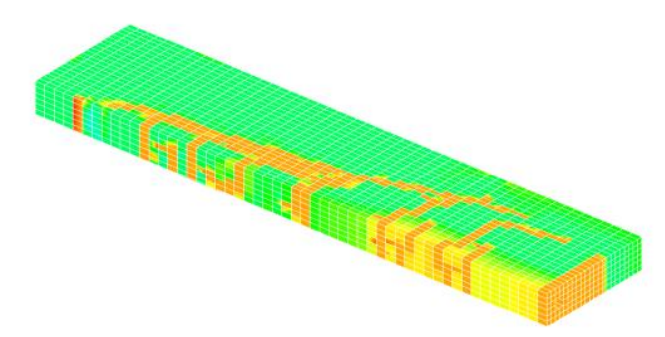

$$
\mathrm{D}=0 \quad \mathrm{D}=1
$$

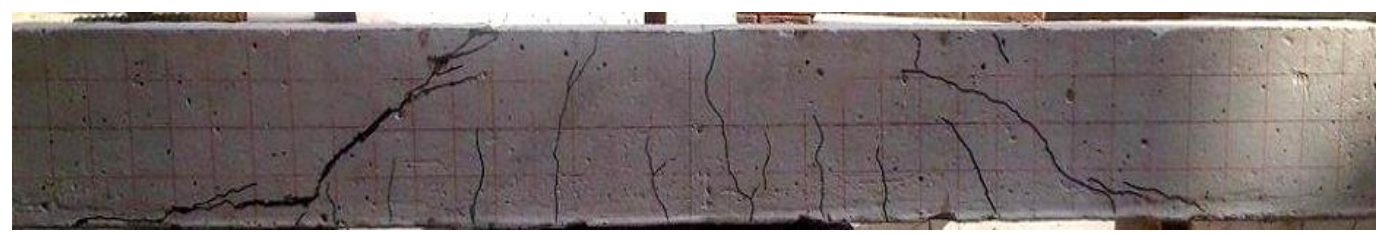

\section{Experimental Crack Pattern}

Figure 14: Computed damage patterns and experimental crack pattern 


\section{CONCLUSION}

Shear damage modelling of RC beam was carried out using Mazars damage model for plain concrete and elastic perfectly plastic behaviour law for steel bars. Interface between steel rebar and concrete was modelled using volumic element with elasto-plastic multilinear hardening behaviour. Simulation results were in good agreement with experimental observations. The simplicity of the simulation approach adopted in this study lies in the fact that most of the model parameters have definite physical meanings and their values may be determined by performing some classical tests on concrete and steel specimens. Numerical simulation in finite element code "CASTEM" did not show any convergence problem.

\section{ACKNOWLEDGEMENT}

The authors are thankful to Civil Engineering Department, UET Lahore for providing the support to complete this research study.

\section{REFERENCES}

[1] J. Mazars. 1984. Application de la mécanique de l'endommagement au comportement non linéaire du béton de structure, PhD Thesis, Ecole Normale Supérieure de Cachan.

[2] CAST3M. (2000). Finite element software. Commissariat à l'Energie Atomique. http://www-cast3m.cea.fr

[3] Sellier, A., Casaux-Ginestet, G., BuffoLacarrière, L., and Bourbon, X. 2010a. "Orthotropic Damage Coupled with Localised Crack Reclosure Processing. Part I: Constitutive Laws". Engineering Fracture Mechanics, Vol. 97, pp. 148-167
[4] Hameed R. 2010. Apport d'un Renfort de Fibres sur les Performances des Structures en Béton Armé pour les Applications Parasismiques (in French), $\mathrm{PhD}$ Thesis. Université de Toulouse-Paul Sabatier III, France.

[5] L. Adelaide, C. Rospars and G. Ruocci. 2013. Numerical modelling of large reinforced concrete specimens based on experimental tests from benchmark concrack, 8th International Conference on Fracture Mechanics of Concrete and Concrete Structures, March 10-14,2013, Toledo-Spain 